\title{
Leadership, facilitation, and relationships are key to countering the waning influence of public health
}

\author{
Kathryn A Oliver research associate \\ Manchester Business School, Manchester M13 9PL, UK
}

Directors of public health and public health more widely may struggle to influence local government processes. Despite regular reorganisations in the NHS, health spending has steadily increased over the past decades. By contrast, many local governments have had their budgets viciously slashed in the 2013 government budget, particularly those in more deprived areas. More to the point, public health staff are employed on NHS terms and conditions which are much more favourable than those usually available to council employees. Relationships, so crucial to effective public health working, are likely to be strained.

Vize claims that directors of public health are influential in local government, and rapid responders to his article call for more finances and support to maximise this influence. ${ }^{1}$ However, studies of leadership consistently suggest that professional expertise is less important than individual characteristics and skills. ${ }^{23}$ Recent research suggests that in fact, directors of public health are rarely universally acknowledged to be influential, with mid-level managers in the NHS and council officers acting as sources of information, providing policy content, shepherding policies through the council policymaking machinery, and generally being creative policy agents. ${ }^{4}$ From this perspective, rather than attempting to lead public health policy, directors will have to work hard to identify these influential individuals and co-opt them to the public health cause.

\begin{abstract}
Most public health policy is created by central government, with local actors discharging statutory duties and implementing policy. Directors of public health will have to learn to balance their own desires to create new policies which aim to affect health with the "business as usual" needs of local government. It is debatable how pertinent clinical training is to prepare directors of public health for these roles. How much preparation do candidates receive in public policymaking, policy analysis, relationship management, facilitation, and leadership? These are crucial skills if public health is to have any impact on the potentially resistant local government sector.
\end{abstract}

\section{Competing interests: None declared.}

1 Vize R. BMJ briefing: meet the new masters of public health. BMJ 2013;346:f4242. (4 July.)

2 Checkland, K, Snow S, McDermott I, Harrison S, Coleman A. "Animateurs" and animation: what makes a good commissioning manager? Journal of Health Services Research and Policy 2012;17:11-17.

3 Mintrom M, Norman P. Policy entrepreneurship and policy change. Policy Studies Journal 2009;37:649-67.

4 Oliver K, de Vocht F, Money A, Everett MG. Who runs public health? A mixed-methods study combining network and qualitative analyses. J Public Health (in press). doi:10.1093/ pubmed/fdt039. 